\title{
Exposure of breeding albatrosses to the agent of avian cholera: dynamics of antibody levels and ecological implications
}

\author{
Amandine Gamble ${ }^{1}$ (D) Romain Garnier ${ }^{2} \cdot$ Audrey Jaeger $^{3,4,5} \cdot$ Hubert Gantelet $^{6} \cdot$ Eric Thibault $^{6} \cdot$ Pablo Tortosa $^{3}$. \\ Vincent Bourret ${ }^{1}$. Jean-Baptiste Thiebot ${ }^{4,7,8} \cdot$ Karine Delord $^{7} \cdot$ Henri Weimerskirch ${ }^{7}$. Jérémy Tornos ${ }^{1}$. \\ Christophe Barbraud ${ }^{7}$. Thierry Boulinier ${ }^{1}$
}

Received: 30 September 2018 / Accepted: 19 February 2019 / Published online: 28 February 2019

(c) Springer-Verlag GmbH Germany, part of Springer Nature 2019

\begin{abstract}
Despite critical implications for disease dynamics and surveillance in wild long-lived species, the immune response after exposure to potentially highly pathogenic bacterial disease agents is still poorly known. Among infectious diseases threatening wild populations, avian cholera, caused by the bacterium Pasteurella multocida, is a major concern. It frequently causes massive mortality events in wild populations, notably affecting nestlings of Indian yellow-nosed albatrosses (Thalassarche carteri) in the Indian Ocean. If adults are able to mount a long-term immune response, this could have important consequences regarding the dynamics of the pathogen in the local host community and the potential interest of vaccinating breeding females to transfer immunity to their offspring. By tracking the dynamics of antibodies against $P$. multocida during 4 years and implementing a vaccination experiment in a population of yellow-nosed albatrosses, we show that a significant proportion of adults were naturally exposed despite high annual survival for both vaccinated and non-vaccinated individuals. Adult-specific antibody levels were thus maintained long enough to inform about recent exposure. However, only low levels of maternal antibodies could be detected in nestlings the year following a vaccination of their mothers. A modification of the vaccine formulation and the possibility to re-vaccinate females 2 years after the first vaccination revealed that vaccines have the potential to elicit a stronger and more persistent response. Such results highlight the value of long-term observational and experimental studies of host exposure to infectious agents in the wild, where ecological and evolutionary processes are likely critical for driving disease dynamics.
\end{abstract}

Keywords Capture-mark-recapture $\cdot$ Disease ecology $\cdot$ Immuno-ecology $\cdot$ Maternal antibodies $\cdot$ Seabird $\cdot$ Serological dynamics $\cdot$ Survival

Communicated by Kevin D. Matson.

Electronic supplementary material The online version of this article (https://doi.org/10.1007/s00442-019-04369-1) contains supplementary material, which is available to authorized users.

Amandine Gamble

amandine.gamble@gmail.com

1 Centre d'Écologie Fonctionnelle et Évolutive (CEFE), UMR CNRS 5175, University of Montpellier, EPHE, University Paul Valéry Montpellier 3, IRD, Montpellier, France

2 Department of Biology, Georgetown University, Washington, DC, USA

3 Processus Infectieux en Milieu Insulaire Tropical, UMR CNRS 9192, INSERM 1187, IRD 249, GIP CYROI, Université de La Réunion, Saint Denis, La Réunion, France

\section{Introduction}

The threat infectious diseases represent for biodiversity has recently been acknowledged and the ability to predict the effect of a pathogen on host populations is an important

4 Réserve Naturelle Nationale des Terres Australes Françaises, Saint Pierre, La Réunion, France

5 Écologie marine tropicale des océans Pacifique et Indien, UMR IRD 250, CNRS, Université de la Réunion, Saint Denis, La Réunion, France

6 Ceva Biovac, Beaucouzé, France

7 Centre d'Études Biologiques de Chizé, UMR CNRS 7372, Université La Rochelle, Villiers en Bois, France

8 National Institute of Polar Research, 10-3 Midori-cho, Tachikawa, Tokyo 190-8518, Japan 
challenge for conservation (Smith et al. 2009; Young et al. 2017). However, it requires understanding the transmission dynamics, which can directly depend on the capacity of hosts to survive infection and to mount an immune response (Keeling and Rohani 2008). An often neglected but critical compartment of the host population is thus the proportion of individuals surviving infection. These individuals may, for instance, constitute a reservoir compartment (Viana et al. 2014) or limit transmission through a herd immunity effect (Iverson et al. 2016). For instance, breeding females can mount a protective immune response and passively transmit it to their offspring (Boulinier and Staszewski 2008). Protection could thus potentially be transferred from surviving individuals to potentially highly susceptible ones. Immunological, and particularly serological, data can be especially useful to track past exposure and quantify epidemiological dynamics (e.g., Pepin et al. 2017; Borremans et al. 2016) while informing on host responses, notably when collected in longitudinal settings (i.e., repeated sampling of individuals; Cizauskas et al. 2014; Buzdugan et al. 2017). Such data can thus be used to estimate the proportion of individuals that survived the previous exposure to infection.

Bacterial agents known for their pathogenicity in domesticated animals are commonly encountered in the wild, but variations in susceptibility among host populations and compartments of host populations are largely underestimated, especially when several strains circulate (Benskin et al. 2009). For instance, avian cholera, caused by Pasteurella multocida $(\mathrm{Pm})$, has been repeatedly implicated in mass mortality events of adult waterfowl and seabirds in the northern hemisphere (e.g., Descamps et al. 2012; Österblom et al. 2004; Wille et al. 2016), while it seems to principally affect nestlings in the seabird community of Amsterdam Island $\left(37^{\circ} 49^{\prime} \mathrm{S}, 77^{\circ} 33^{\prime} \mathrm{E}\right.$, southern Indian Ocean) where recurrent epizooties have been recorded since the mid-1980s (Weimerskirch 2004; Bourret et al. 2018; Jaeger et al. 2018). In addition, some evidence suggest that exposure of waterfowl to $P m$ results in a short-lived immune response (Samuel et al. 2003, 2005a, b), contradicting the suggested, but not fully explored, herd immunity effect leading to avian cholera epizootics fadeout in a population of common eiders (Somateria mollissima; Iverson et al. 2016). Hence, despite avian cholera being an important pathogen for both domestic (Christensen and Bisgaard 2000) and wild birds, basic knowledge on host responses to these bacteria is insufficient to be able to predict its impact on wild populations.

On Amsterdam Island, avian cholera outbreaks recurrently affect seabirds, providing a unique opportunity to gain insights on the responses of long-lived hosts to such a pathogenic agent in the wild. Nestling die-offs appear to particularly affect the locally abundant but globally endangered Indian yellow-nosed albatross (Thalassarche carteri; Weimerskirch 2004; Jaeger et al. 2018). In contrast, impact of the pathogen on adult albatrosses appears limited, with no associated effect on the population (Rolland et al. 2009) despite a few infected individuals found dead (Jaeger et al. 2018). A potential disease-induced mortality of adults could have a strong demographic effect in such a long-lived species. However, it is not clear if adult birds are even exposed to the infectious agent. Notably, the pathogen also threatens the endangered endemic Amsterdam albatross (Diomedea amsterdamensis; Rivalan et al. 2010). Indeed, the entire population of this endemic species breeds in relative close proximity to the affected yellow-nosed albatross population, and predating and scavenging brown skuas (Stercorarius antarcticus) may act as epidemiological bridges between the two populations (Boulinier et al. 2016).

In long-lived species such as albatrosses, antibody responses could be expected to persist longer than in waterfowl, because Procellariiformes are slow-living animals, characterized notably by a long lifespan and a long chickrearing period (Lee 2006; Garnier et al. 2013; Ramos et al. 2014). The maintenance of high individual levels of specific antibodies over several breeding seasons could strengthen herd immunity, but also allow the long-term transfer of potentially protective antibodies from breeding females to offspring via the egg yolk (Gasparini et al. 2002; Garnier et al. 2012). Vaccination against $P m$ is widely considered the most effective way to protect poultry flocks (Ahmad et al. 2014) and autogenous vaccines are routinely used to reduce the risk of emergence of $\mathrm{Pm}$ and the mortality it causes (Christensen and Bisgaard 2000). On Amsterdam Island, vaccination has proven efficient to protect yellownosed albatross nestlings after direct vaccination (Bourret et al. 2018), while non-vaccinated nestlings appear to die without mounting an immune response. If vaccination of adults led to the maintenance of high antibody levels over several breeding seasons, it could open important conservation perspectives by considering the vaccination of breeding females to protect offspring via maternal antibody transfer (Garnier et al. 2012).

In this context, the goal of this study was to improve our understanding of the role of birds that have survived exposure to $\mathrm{Pm}$. This was done by assessing (1) whether adult yellow-nosed albatrosses show serological evidence of exposure to $\mathrm{Pm}$, and if yes, (2) whether they are able to survive subsequent exposure, and (3) whether they can mount and maintain an immune response leading to the transfer of antibodies from breeding females to their offspring. Based on the previous observations suggesting no impact of the epizootics on adult survival in the recent years (Rolland et al. 2009), we explored predictions from two scenarios. In a first scenario, only a small proportion of adults is exposed to the bacteria, for instance, if outbreaks happen in the colony when attendance by adults is low (late in the breeding cycle). In that case, we would 
expect a low-to-null seroprevalence in non-vaccinated adults, independently of any potential disease-induced mortality. In a second scenario, a significant proportion of adults is exposed, survive exposure because diseaseinduced mortality is low, and mount a detectable immune response. In that case, we would expect a moderate-tohigh seroprevalence in non-vaccinated adults. Both scenarios would lead to a high annual survival of adults, with no effect of vaccination on survival, but different seroprevalences. In addition, if high antibody levels are maintained several years following vaccination, maternally inherited antibodies could be detected in young nestlings. To explore these scenarios, we assessed the proportion of adults mounting a humoral immune response to $P m$ exposure, the persistence of antibody levels over several years, adult annual survival, and the transfer of these antibodies to nestlings in both naturally exposed and vaccinated adult yellow-nosed albatrosses breeding on Amsterdam Island. To do so, we set up a capture-recapture program including the monitoring of both non-vaccinated and vaccinated breeders in a colony recurrently affected by avian cholera outbreaks. In addition to the recording of individual resighting histories, breeding adults and their offspring were screened for anti- $P m$ antibodies for 4 consecutive years using two different immunoassays. Considering the threat avian cholera can represent for wild bird populations (Descamps et al. 2012; Phillips et al. 2016; Uhart et al. 2017), the results of the present study may have important implications from basic eco-immunology of host-parasite interactions (Anderson and May 1991) to applied conservation.

\section{Materials and methods}

\section{Study population}

Fieldwork was carried out on Amsterdam Island, in Entrecasteaux cliffs, where approximately 20,000 pairs of yellow-nosed albatrosses nest between September and March each year (Rolland et al. 2009; Electronic Supplemental Material [ESM] 1, Fig. S1.1). Yellow-nosed albatrosses lay one egg per year in the early September and eggs hatch in late November-mid December (Jouventin et al. 1983). Nest attendance by adults is high until January, but drops thereafter. Nestlings are thus on their own on their nest until fledging in April, except for punctual feeding visits from their parents. No albatross is present in Entrecasteaux cliffs between April and August. The study was focused on a naturally delimited subcolony of approximately 250 breeding pairs of yellow-nosed albatrosses.

\section{Vaccine development}

Following a process designed for the poultry industry, an autogenous vaccine was produced from a $\mathrm{Pm}$ strain isolated from the carcass of a sooty albatross nestling found dead in Entrecasteaux cliffs in 2011-2012 (strain reference D2C; Jaeger et al. 2018). This strain was characterized as serotype Heddleston 1, Namioka 7 (Bourret et al. 2018). The vaccine was constituted from killed bacteria of this strain mixed with a mineral oil adjuvant to obtain a water-in-oil emulsion (Ceva Biovac, France). This vaccine has been available since 2013. The formulation was modified in 2015 to induce a higher and more durable response. More details on the vaccine production and its use in albatross nestlings can be found in Bourret et al. (2018).

\section{Field sampling and vaccination design}

During the late incubation and the early chick-rearing periods (November-December) in 2013, 134 breeding adults from 70 nests were captured, blood-sampled $(0.5-1 \mathrm{~mL}$ from the metatarsal veins), and marked with metal and alphanumeric Darvic ${ }^{\circledR}$ plastic leg bands allowing individual identification without recapture. Each captured adult individual received a subcutaneous injection of $0.5 \mathrm{~mL}$ in the back of the neck of either the vaccine (67 "vaccinated" individuals) or a placebo ( $0.9 \%$ sodium chloride solution; 67 "NaCl-injected" individuals). When observed during the following weeks, birds from either group were recaptured and blood-sampled to assess their response to injection (37 $\mathrm{NaCl}$-injected and 34 vaccinated individuals). These birds then also received a second injection of either $\mathrm{NaCl}$ or the vaccine. A short-time booster effect was detected by MAT 1 year but not 2 years after vaccination (ESM 1, Fig. S3.1) and no effect on raw return rate 1 year after vaccination was recorded. Birds injected twice in 2013 were grouped with birds injected once in the following analyses to be conservative with regards to the inter-annual persistence of antibody levels following vaccination. When both partners from a nest were captured, they received the same treatment. Birds from both treatment groups were spatially mixed and distributed throughout the study subcolony.

All banded individual observed within the study subcolony during the three following breeding seasons (2014-2015, 2015-2016, and 2016-2017) were recaptured and blood-sampled to monitor the inter-annual variations of specific antibody level. Most of the captures occurred during the early chick-rearing period and no individual was sampled more than three times within a season.

In 2015, after obtaining the first results of the immunoassays quantifying the anti- $\mathrm{Pm}$ antibody response and interannual antibody persistence (see "Results"), it was decided to attempt to boost the anti- $P m$ antibody levels of the birds 
that had been vaccinated 2 years before. Thirteen individuals were injected in December 2015 with a new formula of the vaccine, while keeping 13 others as control (injecting them with $\mathrm{NaCl}$ ). The use of the new formula of the vaccine, although preventing our ability to disentangle a potential booster effect from an effect of the new vaccine formulation, was motivated by the aim to maximize the potential to obtain the persisting levels of antibodies.

Nestlings of injected successful breeders of the 2014-2015, 2015-2016, and 2016-2017 cohorts were blood-sampled at approximately 5, 10, 30, 60, and 90 days of age to study the transfer and decay of maternal antibodies. In the absence of sexual dimorphism, adult birds were sexed using a molecular technique (Fridolfsson and Ellegren 1999) for comparison of mother's and nestling's antibody levels at hatching. The age of nestlings for which hatching date was not known was estimated using their tarsus length (ESM 1, Fig. S1.2).

Captured individuals were handled on site for only a few minutes. Biosecurity measures were followed to avoid spreading infectious agents between individuals (ESM 1). Within hours of collection, blood samples were centrifuged and plasma extracted. Plasma was kept at $4{ }^{\circ} \mathrm{C}$ in the field, then at $-20{ }^{\circ} \mathrm{C}$ in the laboratory until analyzed. Sample sizes of the different treatment groups are summarized in ESM 1, Table S1.1.

\section{Immunological assays}

Detection of antibodies in plasma samples was used as an indication of exposure to $P m$ antigens (natural or vaccination). Until now, a single strain of $P m$ has been repeatedly isolated from dead birds, rather supporting a single introduction event of the bacterium on the island (Jaeger et al. 2018); seropositivity against $P m$ is thus likely to inform on exposure to this strain, although the circulation of other, potentially less pathogenic, strains cannot be excluded. Given the classical caveats of the use of serology in wildlife (Gilbert et al. 2013; e.g., test sensitivity and specificity bellow unity, individual heterogeneity in response), anti- $\mathrm{Pm}$ antibody levels in plasma samples were measured using two complementary immunoassays detecting different immunoglobulins to maximize the probability to detect past exposure events. First, specific agglutinating antibodies (mostly $\operatorname{IgM}$ and $\operatorname{IgY}$ ) were measured using a microagglutination test (MAT) developed from the $\mathrm{Pm}$ strain D2C isolated on Amsterdam Island (SEROPAST ${ }^{\circledR}$, Ceva Biovac, France; see Bourret et al. 2018). Individuals were considered seropositive if agglutination was observed at the tenfold or more dilution. Results are expressed as titers (log2[last positive dilution/10] + 1). Second, a commercial indirect enzymelinked immunosorbent assay (ELISA) detecting chicken IgY against the Heddleston serotypes 1, 3, and 4 (ID Screen ${ }^{\circledR}$
Pasteurella multocida Chicken and Turkey Indirect, IDvet, France) was used. Results are expressed as optical densities (ODs). The use of anti-chicken IgY to detect yellow-nosed albatross IgY has previously been validated using an experimental design and the positivity threshold was adapted using a method relying on fitting a mixture of normal distributions to the values of ODs (see Garnier et al. 2017). The two assays, thus, only partly overlap in their targeted immunoglobulins: they detect different isotypes, directed against different epitopes, which may or may not be agglutinating. In addition, the MAT was manufactured using the $P m$ strain isolated from the field and does not rely on an intermediate conjugate; as such it is expected to be more sensitive and more specific than the ELISA to detect exposure of albatrosses to Pm on Amsterdam Island (ESM 1). Overall, 697 samples collected from 134 adults and 83 nestlings were analyzed (ESM 1, Table S2.1).

\section{Immunological data analyses}

Annual variations in seroprevalences in "non-vaccinated individuals" (individuals before vaccination and $\mathrm{NaCl}$ injected individuals) were assessed based on the data collected during the late incubation and early chick-rearing period using logistic regressions with serological status (seronegative or seropositive) as the response variable and breeding season as an explanatory variable. As many individuals were sampled several times and a large proportion of individuals were partners, we used generalized linear mixed models in the 'Ime4' R package (Bates et al. 2015), with the individual and the nest as random effects; likelihood ratio test (LRT) $\chi^{2}$ are reported. The Wilcoxon rank-sum test with a Bonferroni correction was used for comparisons of antibody levels between groups of different treatments and between periods. One individual was removed from all the analyses because of consistent surprisingly high ODs (ESM 1, Fig. S2.3). For the figures, the seroprevalences were calculated as the proportion of individuals tested seropositive at least once among all tested individuals during a given period. Sample sizes are reported in the corresponding figures. All statistical analyses were conducted in R 3.3.3 (R Development Core Team 2017) and codes are available in ESM 2.

\section{Capture-recapture analysis}

To explore a potential effect of vaccination on the annual survival of breeding adults, resightings of banded individuals were recorded between the breeding season 2013-2014 and 2016-2017 on the study site and analyzed in a capture-recapture framework (Lebreton et al. 1992). To increase the power of the analysis, 109 non-injected individuals newly marked in December 2014 or December 2015 as 
part of a parallel study (Bourret et al. 2018) were included. Marked individuals were thus divided in three treatment groups: NaCl-injected, vaccinated, and non-injected. The capture histories of marked individuals were built as series of $0 \mathrm{~s}$ (not observed during the breeding season; i.e., dead or alive but not seen) and $1 \mathrm{~s}$ (observed at least once during the breeding season; i.e., alive and seen). Each pair received a different code and a random-effect capture-recapture model (Choquet et al. 2013) was used, allowing to account for the potential dependence of fates (survival and resighting) between the members of pairs. The use of such approaches allows to account for potentially heterogeneous resighting probabilities and thus limits the risk of biased estimations of survival probabilities. First, we used U-CARE to assess the goodness-of-fit of the data set to a Cormack-Jolly-Seber (CJS) model (Choquet et al. 2009a). Then, individual resighting histories were analyzed by running a CJS model in E-SURGE (Choquet et al. 2009b). Our initial model included a fixed vaccination effect, a fixed breeding season effect plus their interaction and a pair random effect on resighting probability, and a fixed vaccination effect and a pair random effect on survival probability (Table 1). Survival probability was constrained to be constant between seasons to allow parameter identifiability (Little et al. 2010). The among pair variation in survival or resighting $(\theta)$ for the $i$ th individual of pair $j$ was modeled as follows:

$\log i t(\theta(i j))=\beta_{0}+b_{j}$,

where $\beta_{0}$ is the mean survival or resighting probability on the logit scale and the $b_{j}$ 's are independent and identically distributed as an univariate normal distribution $N\left(0, \sigma^{2}\right)$ where $\sigma^{2}$ is the variance among pairs (Choquet et al. 2013). Parameters were estimated by maximization of the likelihood (Lebreton et al. 1992) and models including different fixed effects were then compared using AIC corrected for small sample size (AICc; Burnham and Anderson 2002). Random effects of pair were tested using LRTs at the 5\% significant level following Choquet et al. (2013). In total,
243 individuals from 130 nests were included in the analysis, corresponding to 670 resighting events.

\section{Results}

\section{Immune response after natural exposure}

Evidence of natural exposure of adults to $P m$ was found. Seroprevalence according to MAT in non-vaccinated adults was low during the 2013-2014 breeding season (2\%, 3/133; Fig. 1) and significantly higher during the three following seasons $\left(\mathrm{LRT} \chi^{2}=14.21, p<0.01\right.$; ESM 1, Tables S3.1-2), reaching 33\% (8/24) in 2016-2017. After 2014-2015, 7/23 (observed/potential) seroconversion events were observed (ESM 1, Fig. S3.2). Seroprevalence according to ELISA was low and stable during the 4 years of the study, varying between 4 and $7 \%\left(\operatorname{LRT} \chi^{2}=2.04, p=1.00\right.$; ESM 1,

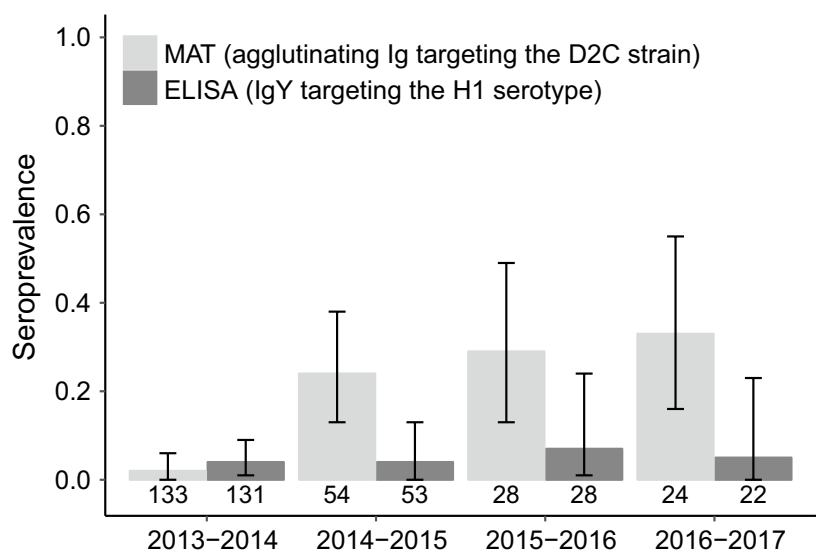

Fig. 1 Prevalence of anti- $P m$ antibodies in non-vaccinated adult yellow-nosed albatrosses after egg-laying measured using an MAT and an ELISA. Sample sizes are reported below the bars; bars represent the $95 \%$ CI
Table 1 Model selection for survival and resighting probabilities of yellow-nosed albatrosses

\begin{tabular}{lllllll}
\hline Model & Survival & Resighting & \#Id.Par. & Deviance & AICc & AICc weight \\
\hline 1 & trt+pair & trt.t+pair & 14 & 603.03 & 631.65 & 0.030 \\
2 & trt+pair & trt.t & 13 & 624.73 & 651.27 & 0.000 \\
3 & trt+pair & trt+pair & 8 & 615.17 & 631.38 & 0.034 \\
4 & trt+pair & t+pair & 8 & 614.97 & 631.18 & 0.038 \\
6 & trt & trt.t+pair & 13 & 604.22 & 630.76 & 0.047 \\
7 & $c$ & trt.t+pair & 11 & 604.65 & 627.04 & 0.302 \\
8 & $c$ & trt+pair & 5 & 616.67 & 626.76 & 0.347 \\
9 & $c$ & t+pair & 5 & 617.76 & 627.85 & 0.201 \\
\hline
\end{tabular}

Fixed effects considered: $c=$ constant, $t r t=$ treatment (non-injected, NaCl-injected and vaccinated), $t=$ breeding season. Random effect: pair. \#Id.Par. is the number of identifiable parameters of the model. Additive effects are denoted by a plus symbol ( + ) and interactions by a dot (.) 
Table S3). As expected, the MAT was thus more sensitive compared to the ELISA for detecting natural exposure.

Most $\mathrm{NaCl}$-injected individuals that seroconverted were resighted the following years (Fig. 2c; ESM 1, Fig. S3.2). Regarding the persistence of specific antibody levels following natural exposure, after 2014-2015, 6/10 seroreversion events were observed based on the MAT results (Fig. 2c; ESM 1, Fig. S3.2). Specific antibody response after natural exposure may thus be short-lived at the inter-annual scale. Overall, these results suggest some exposure to $P m$ in 2014-2015 and the following years.
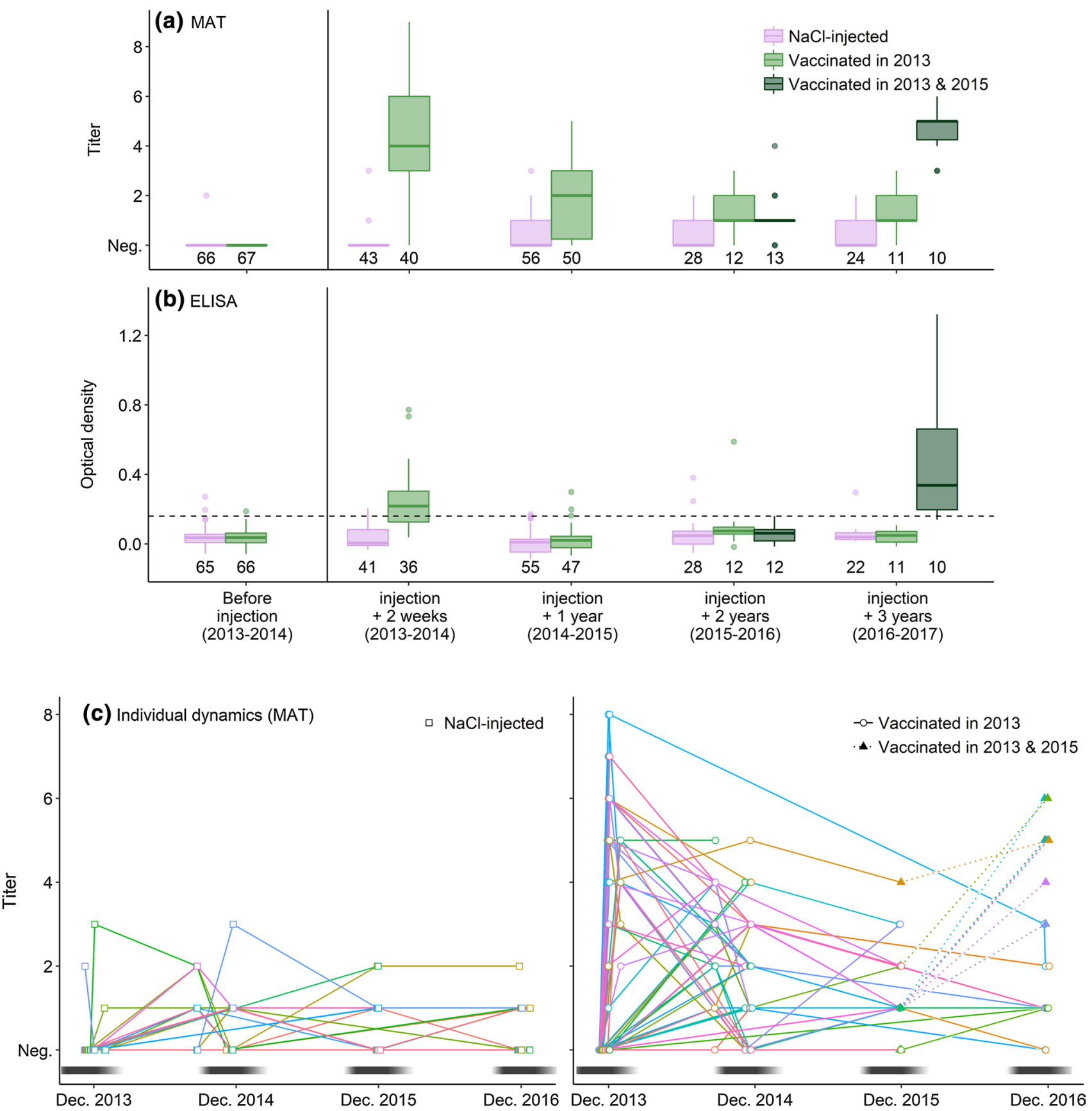

Fig. 2 Quantification of anti-Pm antibodies by MAT (a) or ELISA (b) before and after vaccination and individual antibody-level dynamics (c) in adult yellow-nosed albatrosses after injection of $\mathrm{NaCl}$ or of an autogenous vaccine. a, c MAT non-null titers were considered positive. b ELISA positivity threshold is denoted by a dashed line; sam- ple sizes are reported below the boxes. c Titers were measured by MAT; each line and color represents an individual. Nest attendance by adults is schematized by the black and white line, the darker the line, the higher is the attendance 


\section{Immune response after vaccination}

The initial vaccine injection (received in 2013-2014) induced a strong short-lived immune response. Most individuals responded to vaccination during the weeks following injection (MAT: 85\%, 34/40; ELISA: 61\%, 22/36; ESM 1, Fig. S3.3). Notably, all the individuals recaptured 3 weeks or more after vaccination were MAT-positive $(21 / 21)$. Positive individuals after vaccination showed higher antibody levels in the weeks following injection than naturally exposed individuals (i.e., positive non-vaccinated individuals) during the whole study (MAT: $W=$ 1249, $p<0.01$; ELISA: $W=168, p=0.04$; Fig. 2a, b). Thus, vaccination induced a strong and immediate-specific immune response detected by both MAT and ELISA. One year after vaccination (i.e., 2014-2015), 76\% (38/50) of the recaptured vaccinated individuals had specific antibodies levels detectable by MAT, with a higher proportion among those that had received two injections of the vaccine (17/20 for the birds that received two injections in 2013 versus 14/27 for the birds that received one). At the same time, seroconversion was observed in $30 \%(17 / 56)$ of the recaptured non-vaccinated individuals (Fig. S3.2). Assuming similar exposure to the bacterium of vaccinated and non-vaccinated individuals and $100 \%$ seroconversion of vaccinated individuals, vaccinated individuals had thus a 0.66 probability to remain MAT-positive 1 year after vaccination (see detailed calculation in ESM 1). In contrast, seroprevalence and antibody levels measured by ELISA 1 year after vaccination were not higher in vaccinated individuals than in $\mathrm{NaCl}$-injected individuals (Fig. 2a, b; ESM 1, Fig. S3.3), independently of the numbers of injections received (ESM 1, Fig. S3.1), suggesting no persistence of ELISA-detected antibody levels over a year after the initial vaccination. More precisely, the modeled vaccine response would suggest a peak OD \pm SD of $0.29 \pm 0.08$ reached 26 \pm 9 days after vaccination and a return to seronegativity by $61 \pm 23$ days after vaccination (ESM 1, Fig. S3.5).

The new vaccine injection received 2 years after the initial vaccination induced a longer immune response. All individuals that received that injection in 2015-2016 mounted an immune response detectable by MAT and ELISA 1 year later (i.e., 2016-2017; Figs. 2c, S3.4). These individuals had higher specific antibody levels than 1 year after the initial vaccination (MAT: paired $W=36, p=0.05, n=10$; ELISA: paired $W=55, p<0.01, n=10$ ), and than other individuals that had received two injections in 2013-2014 1 year after vaccination (MAT: $W=147, p<0.01, n=27$; ELISA: $W=$ $140, p<0.01, n=24)$. NaCl-injected and individuals vaccinated in 2013 but not in 2015-2016 (independently from the number of injections received in 2013) had lower levels of specific antibodies in 2016-2017 (Fig. 2a, b). This suggests that the injection of the newly formulated vaccine received
2 years after the initial vaccination induced a stronger and more persistent immune response than the first vaccination.

\section{Maternal transfer of antibodies}

Vaccination of breeding females led to the transfer of maternal antibodies to their offspring. Specific antibodies were detected by MAT in the first blood sample of a high proportion $(>0.50)$ of nestlings of parents vaccinated the previous year (i.e., in the 2014-2015 cohort after vaccination of parents in 2013 and the 2016-2017 cohort after parents had received a new injection in 2015, Fig. 3a). Notably, within the 2014-2015 cohort, 8/9 nestlings of females that had received two vaccine injections the previous year (versus $2 / 10$ for females that had received one) and, within the 2016-2017 cohort, 4/4 nestlings of females that received a new vaccine injection the previous year were detected as
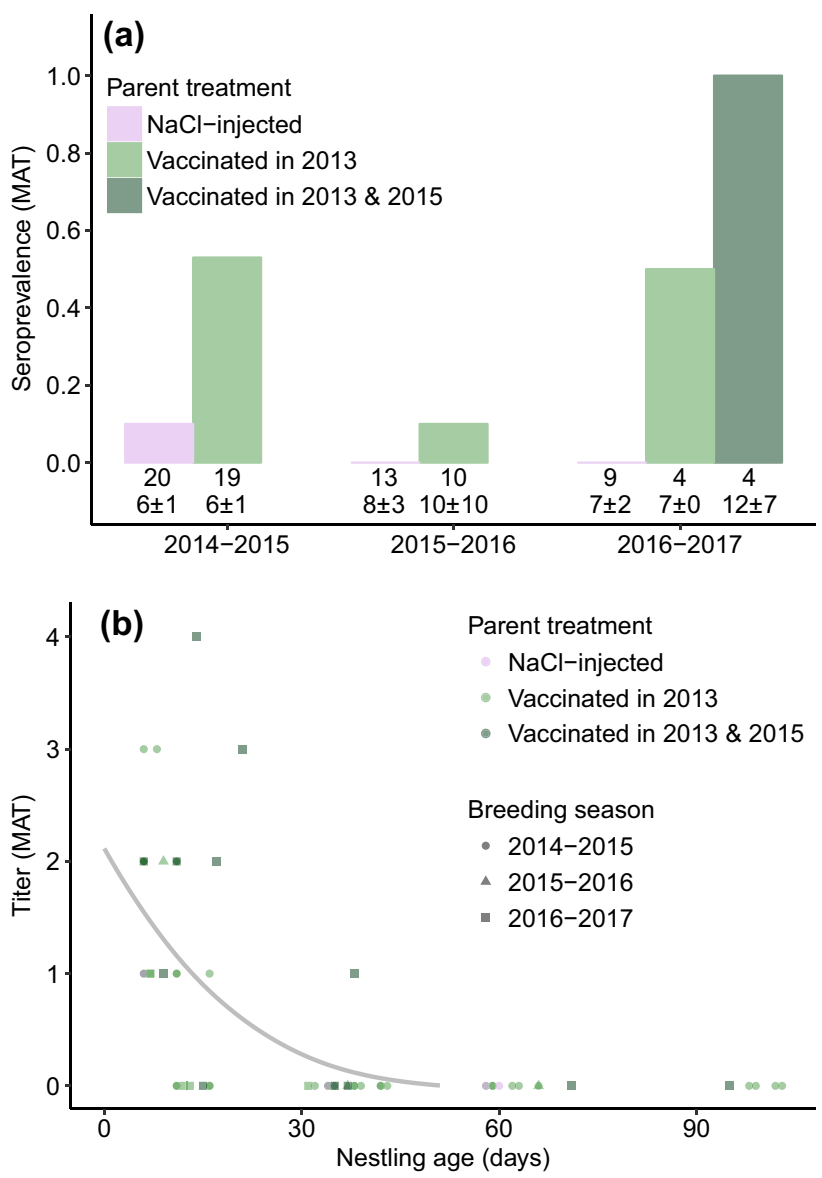

Fig. 3 Prevalence of anti- $P m$ antibodies in the first blood sample of yellow-nosed albatross nestlings (a) and antibody-level decay after hatching (b) measured using MAT. a Sample sizes and mean \pm SD nestling age are reported below the boxes. $\mathbf{b}$ The gray line represents the fitted value of the generalized additive mixed model linking antibody level to age with nestling identity as a random effect (ESM 1); only nestlings with detectable levels of antibodies in their first blood sample are represented 
seropositive. A low proportion of the other nestlings were detected seropositive at their first blood sample (from zero for nestlings of non-vaccinated adults in 2014-2015 and 2015-2016 to 2/4 for nestlings of vaccinated adults 3 years after vaccination). In seropositive nestlings, antibody titers were low at hatching, ranging from 0 to 4 , and decayed after hatching, with most nestlings becoming seronegative by 21 day; only one maintained a detectable antibody level for at least 38 days (Fig. 3b). Of all nestlings, specific antibodies were detected in only two of the 2016-2017 nestlings using ELISA (OD $=0.54$ and 0.81 , aged of 6 and 14 days, respectively). These individuals were associated with females vaccinated in 2013 and 2015 who had high ODs in December $2016(\mathrm{OD}=0.47$ and 1.32 , respectively).

\section{Capture-recapture analysis}

Capture-recapture modeling suggested that adult survival was high and independent of vaccination against $P m$. In more detail, the goodness-of-fit test suggested no lack of fit of the data to a CJS model $\left(\chi^{2}=7.14, p=0.21\right)$. Excluding a pair random effect on resighting probability (Table 1, model 2) markedly increased the AICc value of the initial model. For resighting, the assumption of an absence of variance among the pairs $(\sigma=0)$ was rejected $(\sigma \pm \mathrm{SE}=5.939 \pm$ $2.743, p<0.001)$, indicating high heterogeneity among pairs in resighting probability. Removing the effects of treatment or season on resighting (models 3 and 4 versus 1) greatly increased the deviance, but resulted in large model uncertainty based on AICc values. Including a pair random effect on survival only slightly improved the deviance of the model compared with the treatment survival model (model 1 versus 6). For survival, the assumption $\sigma=0$ could not be rejected $(\sigma \pm \mathrm{SE}=0.794 \pm 1.098, p=0.137)$. Therefore, survival probabilities of individuals associated in pairs were independent. Removing the vaccination effect on survival (model 7) markedly decreased the AICc and a vaccination effect on survival was 5.7 less likely than a constant survival, suggesting that adult survival was independent of vaccination against $\mathrm{Pm}$. Model averaged resighting probabilities were estimated between 0.806 and 0.913 for all years and treatments, and survival probability [CI 95\%] was estimated at $0.924[0.824 ; 0.965]$.

\section{Discussion}

Despite critical implications for the understanding of disease dynamics and the implementation of potential management strategies, temporal patterns of exposure to bacteria and features of host humoral responses are often unknown in wild populations. Here, we provide novel information on these issues in a system involving $P m$ in a population of a long-lived and threatened species, by having repeatedly sampled breeding individuals over a 4 -year period. We found evidence of adult exposure to the pathogen despite high annual survival, highlighting that adults are able to survive exposure. Indeed, the adult survival of Indian yellownosed albatrosses estimated in this study is close to the adult survival of Atlantic yellow-nosed albatrosses (Thalassarche chlororhynchos) estimated on Gough Island (mean \pm SE $0.92 \pm 0.01)$, and higher than the one estimated on Tristan Island ( $0.84 \pm 0.02$; Cuthbert et al. 2003), from where avian cholera has never been reported to our knowledge. Immune response after exposure or vaccination was not life-long but long enough to provide information on the recent epizootics dynamics, especially when using the MAT assay specifically developed with the locally isolated $P m$ strain, suggesting that serology can be a useful tool to track the patterns of $P m$ exposure in the wild. In addition, the detection of specific antibodies in nestlings 1 year after vaccination of breeding females provides insight into possible applications of these tools for conservation, although more work is needed to understand the mechanisms involved in antibody-level persistence.

\section{Immune response after natural exposure}

Our study shows that, despite high annual survival, a large proportion of adult yellow-nosed albatrosses from Amsterdam Island are exposed to the agent of avian cholera. This is consistent with results in geese, suggesting that adult birds can survived exposure to Pm (Samuel et al. 2005a, b), although it had not been quantified. It, however, contrasts with the other waterfowl and seabird populations in which avian cholera induced high adult mortalities (Leotta et al. 2006; Descamps et al. 2012; Österblom et al. 2004; Wille et al. 2016). This heterogeneity is not surprising given what is generally known of the variability of $\mathrm{Pm}$ virulence depending on the strain and the host (Christensen and Bisgaard 2000). On Amsterdam Island, the previous work suggests the circulation of a unique strain of $\mathrm{Pm}$ among seabirds (Jaeger et al. 2018), although more work is needed to confirm the lack of $P m$ diversity, notably by considering potential non-pathogenic strains circulating among healthy animals that could induce cross-reacting immune responses. Individuals surviving infection to a pathogenic agent can play an important role in its maintenance (Viana et al. 2014) and circulation at different spatial scales (Boulinier et al. 2016) by potentially carrying it.

Observations of seroconverting and seroreverting individuals each season since 2014-2015 suggest that the high seroprevalences observed these years correspond to several outbreaks, and not just to the maintenance of antibodies after the 2014-2015 outbreak. Years of high seroprevalences (2014-2015, 2015-2016, and 2016-2017) 
correlate with years of low fledging success recorded in yellow-nosed albatrosses on Amsterdam Island (Bourret et al. 2018; Jaeger et al. 2018), indicating that seroprevalence may be used to track outbreaks. In addition, low seroprevalences were observed in yellow-nosed albatrosses in the first year of the study despite the fact that Pm outbreaks and low fledging success had been recorded in the previous years (Jaeger et al. 2018). This suggests that antibody levels reached in response to exposure to $\mathrm{Pm}$ may not persist over successive breeding seasons. Similarly, levels of antibodies produced by ducks after experimental infection wanes within a few months (Samuel et al. 2003). Short-lasting immunity against $P m$ may, thus, impact the dynamics of epizootics but not be sufficient to lead to fadeouts. These results contradict what has been suggested, but not assessed, in eider ducks exposed to $\mathrm{Pm}$ in the Canadian Arctic (Iverson et al. 2016).

The short-lasting humoral response observed also suggests that individuals might not maintain $P m$ infection over the years and that the contribution of chronically infected adults to the inter-annual maintenance of $\mathrm{Pm}$ may be limited, unless it occurs in seronegative birds. Carrying of the bacteria by seronegative birds has been reported in previous studies on other species (Samuel et al. 2003), but duration is not known (Wobeser 1997 for a review). The main affected species may also not be the sole reservoir. Studies on the roles of brown rats (Rattus norvegicus; Curtis 1983) and brown skuas, which may be year-round residents on the island and probably highly exposed to $P m$ through foraging, are, hence, needed. Brown skuas may notably play a key role as spreaders of $\mathrm{Pm}$ within the island (Boulinier et al. 2016).

\section{Immune response after vaccination}

Vaccination of adult yellow-nosed albatrosses induced an immune response, but detectable antibody levels dropped to below detection within a year in a large proportion of individuals. However, a new injection 2 years after the initial one using a new vaccine formulation induced high levels of antibodies that were maintained over the following year. Considering the frequency of the outbreaks (indicated by low fledging success; Jaeger et al. 2018) and the high seroprevalence in non-vaccinated individuals, it is likely that most of the individuals have been exposed prior to vaccination. The observed difference in antibody-level maintenance between the first and second vaccine injection is thus less likely to be due to a booster effect than to an effect of a difference in the vaccine formulation, although natural (re)exposure or vaccination are likely inducing different responses. Overall, our results open perspectives regarding the maintenance of anti-Pm antibody levels for several years after vaccination.

\section{Maternal transfer of antibodies}

The detection of specific antibodies in nestlings of vaccinated females suggests that, as observed in other seabird host-infectious agent systems (e.g., Gasparini et al. 2002, Garnier et al. 2012), anti-Pm antibodies can be transferred from mother to offspring via the egg yolk. However, low antibody levels in mothers the years following the initial vaccination prevented the transmission of sufficient quantity of antibody for a potentially protective level to be maintained (Grindstaff 2010). Indeed, avian cholera outbreaks are usually recorded several weeks after hatching (Weimerskirch 2004; Bourret et al. 2018). Future work should, thus, focus on testing different vaccination designs in breeding adults (notably based on different vaccine formulations and injection schedules) to assess if it is possible to induce a strong long-lasting immune response. Such response could lead to the transfer of sufficient antibody levels to nestlings over several breeding seasons, as observed in another procellariform species (Ramos et al. 2014), to ensure potentially protective levels at the time of the outbreaks.

\section{Perspectives for disease surveillance and management}

Vaccination of wild populations, despite numerous constraints and keeping in mind the importance of ethical issues, represents a powerful conservation tool (Plumb et al. 2007). Vaccination programs can be developed with different purposes, including elimination of the infectious agent(s) or direct protection of a target population. On Amsterdam Island, attention is strongly focused on the rare endemic Amsterdam albatross, but other species, potentially involved in Pm circulation or maintenance, also need to be considered. Avian cholera appears to kill thousands of nestlings of the locally abundant yellow-nosed albatross and their immunization, active by direct vaccination (previously proven in Bourret et al. 2018), or passive by maternally transferred antibodies, could thus be a potentially important management tool if maintained over series of years to protect several cohorts. Vaccination of parts of the yellow-nosed albatross local population to limit negative demographic effects and vaccination of brown skuas to limit the spread of the bacteria within the island or direct precautionary vaccination of Amsterdam albatrosses are possible options that could be considered. The use of vaccination for conservation in Procellariiformes would benefit from the longevity and faithfulness of individuals to their breeding site, which should help to strengthen potential local herd immunity effects. In any case, a priori modeling would be a useful step to determine which components of the community may be more pertinent to vaccinate and with which potentially optimal design (Haydon 
et al. 2006; Garnier et al. 2012). The results of the current study thus clearly open perspectives, but empirical work is still required regarding the potential effects of vaccination on shedding and nestling protection via maternal antibody transfer.

In addition, our study revealed that serology could be useful to track the circulation of a supposedly highly lethal disease agent in the wild. This approach is not available for all systems and interpretation of the results depends on the temporal persistence of antibodies following infection (Gilbert et al. 2013; Garnier and Graham 2014; Metcalf et al. 2016). However, recent examples have illustrated that serology could be useful to detect individuals surviving to supposedly highly lethal infectious agents (e.g., Mulangu et al. 2018 for the Ebola virus, Cizauskas et al. 2014 for the anthrax bacillus). In addition, when serological data are rigorously analyzed or combined with other data sources, they can bring valuable information on epidemiological dynamics and recent advances show that, despite being an old tool, it still show promise (Borremans et al. 2016; Buzdugan et al. 2017; Pepin et al. 2017).

Overall, our results highlight the value of detailed observational and experimental studies of the dynamics of host exposure to infectious agents in the wild, where ecological and evolutionary processes are likely critical for driving disease dynamics, and such knowledge may be useful to inform management plans.

Acknowledgements We are grateful to Nicolas Giraud, Marine Bely, Romain Bazire, Rémi Bigonneau, Hélène Le Berre, David Hémery, and Marine Quintin for their help in the field, and Cédric Marteau, Camille Lebarbenchon, and Raul Ramos for help at various stages of the work. We also thank Stéphanie Lesceu and Khadija Mouacha (IDvet, France) and Nelly Lesceau and her team (Ceva Biovac, France) for technical help.

Author contribution statement $\mathrm{TB}$ and RG conceived the idea of this work; TB, RG, AG, JT, KD, HW, and CB designed the study; HG and ET conceived the vaccine and the MAT. JT, TB, AG, AJ, KD, VB, and JBT collected the data; AG ran the ELISA and analyzed the serological data; AG and CB ran the capture-recapture analyses; AG led the writing of the manuscript and all authors contributed substantially to the drafts and gave final approval for publication.

Funding This work was funded by the French Polar Institute (IPEV programs ECOPATH-1151 and ORNITHOECO-109), the Agence Nationale de la Recherche (project EVEMATA 11-BSV7-003), the Réserve Nationale des Terres Australes Françaises, and the Zone Atelier Antarctique. This paper is a contribution to the Plan National d'Action Albatros d'Amsterdam. AG was supported via a Ph.D. fellowship from French Ministry of Research and VB through a CeMEB LabEx post-doctoral fellowship.

\section{Compliance with ethical standards}

Conflict of interest We declare no conflict of interest.
Permits The experimental design was approved by the Comité de 1'Environnement Polaire (TAAF A-2013-71, A-2014-134, A-2015107, and A-2016-80) and the French Ministry of Research (04939.03).

Data accessibility Supplementary data associated with this article can be found on the OSU OREME online repository at https://doi. org/10.15148/c8256ec7-b5e1-4cc4-8429-7bf6cc79263c.

\section{References}

Ahmad TA, Rammah SS, Sheweita SA, Haroun M, El-Sayed LH (2014) Development of immunization trials against Pasteurella multocida. Vaccine 32:909-917

Anderson RM, May RM (1991) Infectious diseases of humans: dynamics and control. Oxford University Press, Oxford

Bates D, Mächler M, Bolker B, Walker S (2015) Fitting linear mixedeffects models using lme4. J Stat Softw 2015:67

Benskin CMH, Wilson K, Jones K, Hartley IR (2009) Bacterial pathogens in wild birds: a review of the frequency and effects of infection. Biol Rev 84:349-373

Borremans B, Hens N, Beutels P, Leirs H, Reijniers J (2016) Estimating time of infection using prior serological and individual information can greatly improve incidence estimation of human and wildlife infections. PLoS Comput Biol 12:e1004882

Boulinier T, Staszewski V (2008) Maternal transfer of antibodies: raising immuno-ecology issues. Trends Ecol Evol 23:282-288

Boulinier T, Kada S, Ponchon A, Dupraz M, Dietrich M, Gamble A, Bourret V, Duriez O, Bazire R, Tornos J, Tveraa T, Chambert T, Garnier R, McCoy KD (2016) Migration, prospecting, dispersal? What host movement matters for infectious agent circulation? Integr Comput Biol 56:330-342

Bourret V, Gamble A, Tornos J, Jaeger A, Delord K, Barbraud C, Tortosa P, Kada S, Thiebot J-B, Thibault E, Gantelet H, Weimerskirch H, Garnier R, Boulinier T (2018) Vaccination protects endangered albatross chicks against avian cholera. Conserv Lett 11:e12443

Burnham KP, Anderson DR (2002) Model selection and multimodel inference: a practical information-theoretic approach. Springer, Berlin

Buzdugan SN, Vergne T, Grosbois V, Delahay RJ, Drewe JA (2017) Inference of the infection status of individuals using longitudinal testing data from cryptic populations: towards a probabilistic approach to diagnosis. Sci Rep 7:1111

Choquet R, Lebreton J-D, Gimenez O, Reboulet A-M, Pradel R (2009a) U-CARE: utilities for performing goodness of fit tests and manipulating capture-recapture data. Ecography 32:1071-1074

Choquet R, Rouan L, Pradel R (2009b) Program E-SURGE: a software application for fitting multievent models. Modeling demographic processes in marked populations. Springer, Berlin, pp 845-865

Choquet R, Sanz-Aguilar A, Doligez B, Nogué E, Pradel R, Gustafsson L, Gimenez O (2013) Estimating demographic parameters from capture-recapture data with dependence among individuals within clusters. Methods Ecol Evol 4:474-482

Christensen JP, Bisgaard M (2000) Fowl cholera. Rev Sci Tech (Int Office Epizoot) 19:626-637

Cizauskas CA, Bellan SE, Turner WC, Vance RE, Getz WM (2014) Frequent and seasonally variable sublethal anthrax infections are accompanied by short-lived immunity in an endemic system. J Anim Ecol 83:1078-1090

Curtis PE (1983) Transmission of Pasteurella multocida infection from the brown rat (Rattus norvegicus) to domestic poultry. Vet Rec 113:133-134 
Cuthbert R, Ryan PG, Cooper J, Hilton G (2003) Demography and population trends of the Atlantic yellow-nosed albatross. Condor 105:439-452

Descamps S, Jenouvrier S, Gilchrist HG, Forbes MR (2012) Avian cholera, a threat to the viability of an Arctic seabird colony? PLoS One 7:e29659

Fridolfsson A-K, Ellegren H (1999) A simple and universal method for molecular sexing of non-ratite birds. J Avian Biol 30:116-121

Garnier R, Graham AL (2014) Insights from parasite-specific serological tools in eco-immunology. Integr Comp Biol 54:363-376

Garnier R, Ramos R, Staszewski V, Militão T, Lobato E, GonzálezSolís J, Boulinier T (2012) Maternal antibody persistence: a neglected life-history trait with implications from albatross conservation to comparative immunology. Proc R Soc Lond B Biol Sci 279:2033-2041

Garnier R, Boulinier T, Gandon S (2013) Evolution of the temporal persistence of immune protection. Biol Lett 9:20130017

Garnier R, Ramos R, Sanz-Aguilar A, Poisbleau M, Weimerskirch $\mathrm{H}$, Burthe S, Tornos J, Boulinier T (2017) Interpreting ELISA analyses from wild animal samples: some recurrent issues and solutions. Funct Ecol 31:2255-2262

Gasparini J, McCoy KD, Tveraa T, Boulinier T (2002) Related concentrations of specific immunoglobulins against the Lyme disease agent Borrelia burgdorferi sensu lato in eggs, young and adults of the kittiwake (Rissa tridactyla). Ecol Lett 5:519-524

Gilbert AT, Fooks AR, Hayman DTS, Horton DL, Müller T, Plowright R, Peel AJ, Bowen R, Wood JLN, Mills J, Cunningham AA, Rupprecht CE (2013) Deciphering serology to understand the ecology of infectious diseases in wildlife. EcoHealth 10:298-313

Grindstaff JL (2010) Initial levels of maternally derived antibodies predict persistence time in offspring circulation. J Ornithol 151:423-428

Haydon DT, Randall DA, Matthews L, Knobel DL, Tallents LA, Gravenor MB, Williams SD, Pollinger JP, Cleaveland S, Woolhouse MEJ, Sillero-Zubiri C, Marino J, Macdonald DW, Laurenson MK (2006) Low-coverage vaccination strategies for the conservation of endangered species. Nature 443:692-695

Iverson SA, Gilchrist HG, Soos C, Buttler EI, Harms NJ, Forbes MR (2016) Injecting epidemiology into population viability analysis: avian cholera transmission dynamics at an Arctic seabird colony. J Anim Ecol 85:1481-1490

Jaeger A, Lebarbenchon C, Bourret V, Bastien M, Lagadec E, Thiebot J-B, Boulinier T, Delord K, Barbraud C, Marteau C, Dellagi K, Tortosa P, Weimerskirch H (2018) Avian cholera outbreaks threaten seabird species on Amsterdam Island. PLoS One 13:e0197291

Jouventin P, Roux J-P, Stahl J-C, Weimerskirch H (1983) Biologie et frequence de reproduction chez l'albatros à bec jaune (Diomedea chlororhynchos). Le Gerfaut 73(2):161-171

Keeling MJ, Rohani P (2008) Modeling infectious diseases in humans and animals. Princeton University Press, Princeton

Lebreton J-D, Burnham KP, Clobert J, Anderson DR (1992) Modeling survival and testing biological hypotheses using marked animals: a unified approach with case studies. Ecol Monogr 62:67-118

Lee KA (2006) Linking immune defenses and life history at the levels of the individual and the species. Integr Comp Biol 46:1000-1015

Leotta GA, Chinen I, Vigo GB, Pecoraro M, Rivas M (2006) Outbreaks of avian cholera in Hope Bay, Antarctica. J Wildl Dis 42:259-270

Little MP, Heindenreich WF, Guangquan L (2010) Identifiability and redundancy: theoretical considerations. PLoS One 5:e8915
Metcalf CJE, Farrar J, Cutts FT, Basta NE, Graham AL, Lessler J, Ferguson NM, Burke DS, Grenfell BT (2016) Use of serological surveys to generate key insights into the changing global landscape of infectious disease. Lancet 388:728-730

Mulangu S, Alfonso VH, Hoff NA, Doshi RH, Mulembakani P, Kisalu NK, Okitolonda-Wemakoy E, Kebela BI, Marcus H, Shiloach J, Phue J-N, Wright LL, Muyembe-Tamfum J-J, Sullivan NJ, Rimoin AW (2018) Serologic evidence of ebolavirus infection in a population with no history of outbreaks in the Democratic Republic of the Congo. J Infect Dis 217:529-537

Österblom H, Van Der Jeugd HP, Olsson O (2004) Adult survival and avian cholera in common guillemots Uria aalge in the Baltic Sea. Ibis 146:531-534

Phillips RA, Gales R, Baker GB, Double MC, Favero M, Quintana F, Tasker ML, Weimerskirch H, Uhart M, Wolfaardt A (2016) The conservation status and priorities for albatrosses and large petrels. Biol Conserv 201:169-183

Plumb G, Babiuk L, Mazet J, Olsen S, Rupprecht C, Pastoret PP, Slate D (2007) Vaccination in conservation medicine. Rev Sci Tech (Int Office Epizoot) 26:229-241

Ramos R, Garnier R, González-Solís J, Boulinier T (2014) Long antibody persistence and transgenerational transfer of immunity in a long-lived vertebrate. Am Nat 184:764-776

Rivalan P, Barbraud C, Inchausti P, Weimerskirch H (2010) Combined impacts of longline fisheries and climate on the persistence of the Amsterdam Albatross Diomedia amsterdamensis. Ibis 152:6-18

Rolland V, Barbraud C, Weimerskirch H (2009) Assessing the impact of fisheries, climate and disease on the dynamics of the Indian yellow-nosed albatross. Biol Conserv 142:1084-1095

Samuel MD, Shadduck DJ, Goldberg DR, Johnson WP (2003) Comparison of methods to detect Pasteurella multocida in carrier waterfowl. J Wildl Dis 39:125-135

Samuel MD, Shadduck DJ, Goldberg DR (2005a) Avian cholera exposure and carriers in greater white-fronted geese breeding in Alaska, USA. J Wildl Dis 41:498-502

Samuel MD, Shadduck DJ, Goldberg DR, Johnson WP (2005b) Avian cholera in waterfowl: the role of lesser snow and Ross's geese as disease carriers in the Playa Lakes Region. J Wildl Dis 41:48-57

Smith KF, Acevedo-Whitehouse K, Pedersen AB (2009) The role of infectious diseases in biological conservation. Anim Conserv 12:1-12

Uhart MM, Gallo L, Quintana F (2017) Review of diseases (pathogen isolation, direct recovery and antibodies) in albatrosses and large petrels worldwide. Bird Conserv Int 2017:1-28

Viana M, Mancy R, Biek R, Cleaveland S, Cross PC, Lloyd-Smith JO, Haydon DT (2014) Assembling evidence for identifying reservoirs of infection. Trends Ecol Evol 29:270-279

Weimerskirch H (2004) Diseases threaten Southern Ocean albatrosses. Polar Biol 27:374-379

Wille M, McBurney S, Robertson GJ, Wilhelm SI, Blehert DS, Soos C, Dunphy R, Whitney H (2016) A pelagic outbreak of avian cholera in North American gulls: scavenging as a primary mechanism for transmission? J Wildl Dis 52:793-802

Wobeser GA (1997) Diseases of wild waterfowl. Springer, Boston

Young HS, Wood CL, Kilpatrick AM, Lafferty KD, Nunn CL, Vincent JR (2017) Conservation, biodiversity and infectious disease: scientific evidence and policy implications. Philos Trans R Soc Lond B Biol Sci 372:20160124 